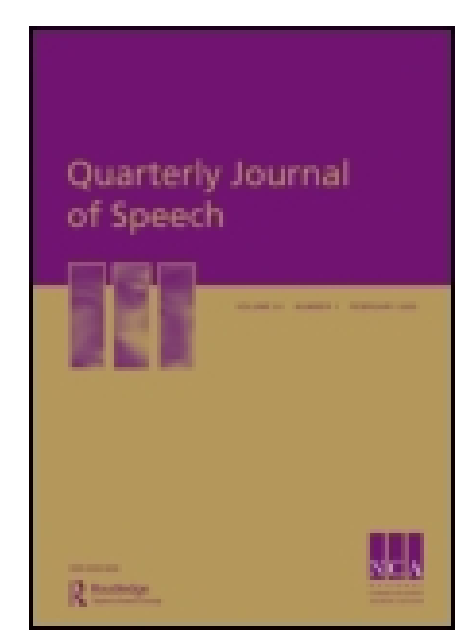

Quarterly J ournal of Speech

Publication details, including instructions for authors and subscription information:

http:// www.tandfonline.com/loi/ rqjs20

\title{
Theories of expression: Some criticisms
}

C. H. Woolbert ${ }^{\text {a }}$

aniversity of Illinois

Published online: 06 J un 2009

To cite this article: C. H. Woolbert (1915) Theories of expression: Some criticisms, Quarterly J ournal of Speech, 1:2, 127-143, DOI: 10.1080/00335631509360473

To link to this article: http:// dx. doi. org/ 10.1080/00335631509360473

PLEASE SCROLL DOWN FOR ARTICLE

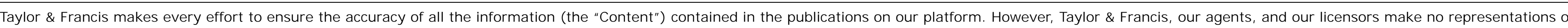

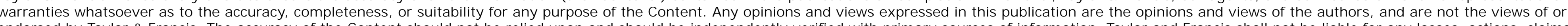

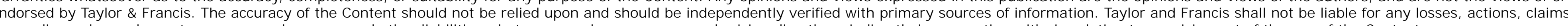
proceedings, demands, costs, expenses, damages, and other liabilities whatsoever or howsoever caused arising directly or indirectly in connection with, in relation to or arising out of the use of the Content.

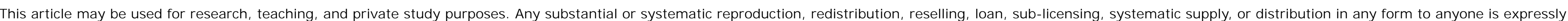
forbidden. Terms \& Conditions of access and use can be found at http://www.tandfonline.com/page/terms-and-conditions 


\section{THEORIES OF EXPRESSION: SOME CRITICISMS}

C. H. WOOLBERT

University of Illinois

A A preliminary to the task of investigating the basis of teach-
ing oral expression, it ought to be of value for the Quarterly to publish, first, a few opinions. These will make good points of departure for the carrying on of research. Without any doubt the one greatest problem that confronts the public-speaking profession is that of oral expression. What is it, anyway? When is it expression and when is it something else? How is it to be taught to a class? Is there any hope for an ultimate "school" that will in reality be, not a school at all, but a science? We are sometimes told that as an academic discipline we have not arrived; we have no right to claim a scientific basis because we cannot agree on what expression is and how it is to be brought about in others. We do not even agree upon the merit of different kinds of finished products. Our tastes determine our theory and our tastes differ as the poles. We are prone to parade our successes and hide our failures. We seem about as far from standardization as when we started; and for the simple reason that we have not applied the test of research to our "systems." As a preliminary to the task, therefore, will not the statement of some opinions draw out some facts and also suggest some problems? Let us not assume that we are getting to the bottom of anything, but let us agree that in this way we can start something that we ought to get at and finish.

At the beginning it will be well to lay down some postulates that will probably meet with a large measure of acceptance. There are certain fundamental facts that ought to be agreed to by the advocates of any current "system." With these stated we shall be in position to make clear the differences in "systems" and some virtues and shortcomings of any or all.

I. In the first place there will not be the slightest disagreement with the proposition that oral expression is and aims to be a matter 
of carrying thought from one mind to another by means of the voice. Stating it more specifically yet, it is a matter of carrying thought by means of sounds made by the voice of the speaker. Eliminating for the present the consideration of action-gesture and posture, that which strikes the eye only-oral expression, then, is a matter of carrying thought by means of certain sounds made by the vocal organs of the spealker for the enlightenment or delight of the listener.

2. These sounds that the speaker makes are intended to excite the apprehensive function of the listener and to let him know what it is that the speaker wishes to transmit. They are not for the benefit of the speaker primarily; these sounds are uttered in order to influence the thinking, feeling, or conduct of the man who hears them. Expression to this extent is fundamentally an objective matter. Its prime aim is to influence others by means of what these others receive through the ear. It is not to be thought of as merely relieving the speaker's desire to make certain vocal sounds or to utter certain thoughts to the air; it is an enterprise that aims at a target outside of the self.

3. Speaking in terms of psychology, what actually reaches the consciousness of the hearer is sensation of sound. The notion of "carrying thought" reduces itself flatly to this. But these sounds carry meaning; so we may say, then, that what the speaker gets into the consciousness of the listener is certain meanings that the sounds carry. What happens in the mind of the hearer is as follows: the sounds carry meanings to the hearer; these meanings are meanings of ideas, images, concepts, but of ideas, images, and concepts that allready exist in the mind of the listener. ${ }^{6}$ Carrying thought" might much better be changed, from one point of view, to stirring thought; sounds cannot carry any meaning not already present in the mind of the hearer. The meanings the sounds carry can be cumulated, piled up, broken up, dissolved, added, subtracted, multiplied, divided into infinite permutations and combinations. In this way new images are made, new ideas established, new concepts set up, and new judgments formed. This it is that happens in the mind of the hearer when we say that we carry our thought to him. Yet the only thing that is actually sent him is certain vocal sounds, certain sound waves that carry meaning. 
4. Expression, then, is a matter of so uttering sounds that the right meanings will be stirred in the mind of the hearer. It becomes, therefore, a matter of choice, of selection, of accepting and rejecting. In other words, it must conform to the standards of all artistic selection; it is an art. It is the art of selecting and using sounds on such a basis as to induce the maximum of accuracy in the apprehensive functions of the mind of the listener. Expression is successful only when it leaves the hearer understanding clearly what the speaker means; what his individual words mean, what his sentences mean, and what his whole attitude means. It is, then, a matter of carrying clearness of meaning. This is what we have in mind when we talk about "carrying thought."

5. The differences in the various theories of expression arise from differences as to what constitutes the proper way to choose the sounds with which the thought is carried. One "school" says choose them one way; another calls this method of selection all wrong and chooses another way. So any discussion of these theories must focus on this issue: How shall we teach boys and girls to choose the sounds they are going to make in order to carry the right meanings to the hearer? By what method do you show others how to tell when they are using the right sounds and when they are not? What is the best principle for discussing in the classroom the basis of selection for insuring the carrying of the right meaning with the sounds the voice makes to influence others?

6. There are certain subsidiary considerations that can be readily agreed to, yet are always emphasized as of vital importance in the defense of "systems": (a) Honesty and sincerity are essential to artistic effort; (b) expression at its best is the man himself speaking out; (c) the standard of effectiveness in getting the desired results is the one that must be upheld at all times; $(d)$ in order to get at a valid teaching method, we must find and deal with the right kind of elements.

a) The Rush "elements system."-So much has been uttered by way of condemnation of the so-called "elements system," based on Rush principles, that comparatively little needs to be said of it in this paper. The objections levied against it are that it produces artificiality; that it is not artistic; that it does not offer a natural method of expression; that the mind does not think in terms of 
pitch, rate, force, and quality; that to teach students matters of ditones, triads, discrete cadence, orotund quality, or median stress is to hold their attention to the wrong suggestion and to produce expression that is artificially inflated or unintelligently fantastic; that it subordinates thought to set formulas, and sacrifices matter to manner. Teaching by means of Rush "elements" chooses vocal sounds on the wrong basis; it is a choice that can easily be too arbitrary, eccentric, erratic, meaningless.

Without attempting here to go into the merits of these contentions, some of which will stand against at least the old-time teaching of this school, it will be well to point out that some of the most efficient teaching of public speaking in the country in an academic way is being done with emphasis in class on these elements of pitch, time, force, and quality. Whatever the paper arguments may be pro and con, the fact stands out that the "elements" are making good in the classroom in some very notable instances. It is doubtful if any three institutions in the country can show a larger number of students who can make a good showing on the platform than the University of Michigan, Northwestern University, and Ohio Wesleyan; and all three use some form of "elements" instruction. This is mentioned here because the attack upon the "elements system" has been particularly enthusiastic and dogmatic.

We can sum up the status of the Rush "elements" as a factor in expressional pedagogy by saying that while the arguments against their use seem very impressive, yet the elements are actually used in a way to get good results in spite of these arguments. Obviously there is a leak somewhere in the philosophy of the opponents. We shall have more to say of these elements later.

b) Imitation.-Dr. Curry, in his Lessons in Vocal Expression (p. 2), points to only two prevailing "systems" at the time he wrote (I895): the "elements" and imitation. Little need be said concerning imitation as a system by itself. There has been a pronounced tendency of late years to thrust imitation into its proper place. All teaching must rest on example and precept; but neither of these can usurp the function of the other. Hence teaching by imitation only is practically taboo. Only in a few coaching schools 
does it survive. We can dismiss it by saying of it that while a teacher, to achieve a maximum of efficiency, ought to be able to give adequate demonstration of what he is trying to teach others to do, still imitation and imitation only is a thoroughly discredited method of teaching expression. We do not at this juncture need to go farther into the why; it is simply out, and out to stay.

c) "Think the thought."-We come now to the "system" that has probably had a more widespread influence for two decades than any other-the "think-the-thought" school; the method that insists that expression is entirely dependent upon the intent of the expressing mind to utter thoughts sincerely and honestly. It teaches that to make a student conscious of pitch, rate, force, and quality is to interfere with the spontaneous outpouring of the soul. To make him in any way aware of the mechanism of speech while he is speaking is to interfere with honesty and genuineness of thinking. The mind is the real expressor; get the mind in the right condition and the rest of the organism, particularly the voice, cannot help but react in the proper manner, at least $a$ proper manner. Train the mind to master its emotions and its logical processes-all the forms of its thinking-and there will be no need of analyzing tone or vocal mechanics to their physical elements.

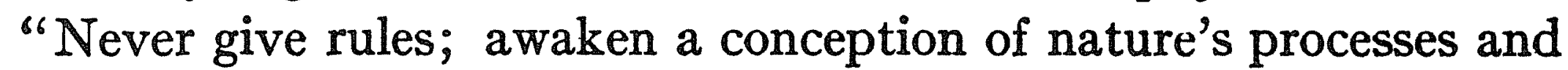
methods, and test expression by truthfulness to what is natural." "True practice is a struggle to realize an idea." "Never say that a certain piece must be given with a certain 'tone.' Thought and passion are greater than any tone."

Probably this "system" prevails in a larger number of colleges than does any other. It came into existence as a natural reaction against excesses and absurdities in the teaching of the Rush "elements" and the method of imitation. Because these excesses and absurdities had been so marked and had been so offensive, particularly to those of academic mind, "think the thought" gained wide popularity, especially in centers where moderation and sincerity were virtues carefully fostered. It is safe to say that very much the most of college instruction in expression in the eastern colleges is based on the principles of the "thought school" of expression;

× S. S. Curry, Lessons in Vocal Expression, p. 9, Boston, I895. 
and its influence, at least as a corrective, has been felt everywhere. It probably brings more defenders to its standard than any other.

Yet there are some very valid criticisms to be laid against it. Like all other current systems it assumes to have found for expression an ultimate basis. It is on this score that it can be attacked with considerable vigor.

In the first place, "thought" teaching leaves out of consideration the fact that oral expression is aimed at a hearer, that the hearer gets a reaction only as he grasps certain meanings, that the speaker's business is to attend to these objective meanings just as much as to indulge in honest subjective self-expression. It assumes that if the speaker is only honest with himself, the hearer simply must receive the truth and the truth only; that if the speaker or reader has perfect control of his own thought processes, what he utters must be received as he himself sees and feels it. But there is a fundamental weakness in this. It is too tenuously theoretic. It leaves out common human frailty. Of course, anybody will agree that an ideal human mind co-operating with an ideal audience will choose the ideal means of uttering sounds so as to carry the right meaning to the audience. Speakers will say the right thing and in the right way and so stir in the hearer's mind the right ideas, images, and meanings.

But it is only under ideal conditions that "thought" methods can make a complete system of instruction. Imperfect minds and imperfect voices cannot work together in that fine conjunction that brings perfect results. Their union is more likely to bring forth monstrosities than specimens of perfection. Most thinking uttered by voices that belong with it carries wrong meanings. True, the "thought" advocates are everlastingly sound in insisting that there is profit for every student in struggling "to observe himself, to become conscious of his possibilities, of his ideal as well as his actual, and to compare the one with the other." But the speaker is only half the transaction; the hearer is just as much as expressor of thought as the spealker. It is his mind that is to be affected; otherwise expression is aimed only at the empty air. Speaker and audience bear an equal part in the commerce of

I Curry, op. cito, p. 9. 
thoughts. Oral expression is vain without the hearer, for he must be made to "think the thought" just as much as the speaker.

Now, can an imperfect expressing mind make sure of getting its thought across to a receiving mind, perfect or imperfect, by merely subjective methods? That is the crux of the issue. Is a theory complete and all-sufficing when it ignores the receiving apparatus of the listener? The answer seems clear: There are certain stones lacking in the foundation, and the whole structure is weakened by their absence. Speaking to another is emphatically a different process from clarifying and organizing one's own thoughts, however valuable these may be as contributing factors. In reality, using the voice to carry thought has in it elements of artificiality; it is a matter of using a tool, an intermediary, a means to an end. It has to employ artifices, devices, ways, means, methods, schemes, "stunts" - even tricks can be so employed as to get aimed-at results. It uses arbitrarily chosen symbols called words; it calls for the use of devices of rhetoric and composition; it compels a careful selection of ideas, a culling out of the bad and an accentuating of the good. And in the same way it demands a selecting of tones, devices of the vocal apparatus, of ways and methods of choosing and using the infinite variety of sounds the human voice is capable of making. All these devices and artifices must be at the beck and call of the speaker if he is to succeed in carrying his meaning to his hearer; if he is to be effective in leaving a desired impression upon the listener's mind.

Is it, now, condemnation to say that expression must employ artifices; that it must be artful? Piano-playing is full of artifices; sculpturing uses them; architecture, even, reduces them to a table of logarithms; singing abounds in them, and painting could not exist without them. Clearly it is not a condemnation of art to say that it employs artifices; it is, rather, an explanation of it; it helps mark its boundaries from that which is not-art. It has to do so; otherwise it is not artistic. Consider the difference between what the camera catches and what the painter selects. Seldom indeed does a camera's drag-net disclose a work of art; the artist's careful selection - his picking and choosing-is required to make art. True, a perfect camera and a perfect composition of landscape, say, 
can hit an artistic effect-but only about as often in actual occurrence as a perfect, natural-born speaker faces an equally perfect audience. Such results are only fortuitous; art is engrossed almost always in compelling imperfect nature-from the artistic point of view - to stand aside so that the artist can force an artistically perfect effect out of imperfect means.

Therefore, it is not an impeachment of a speaker's or reader's sincerity to say that he uses artifices to produce his effects. Of course, the user of artful devices is always in danger, just like the man who works at a buzz saw or "totes" a gun; both of these instruments are very easily capable of abuse and are dangerous in the hands of a careless or evil-disposed person. Obviously, honest intentions and clearly conceived purposes are a great aid in expression; but they are not the whole of the art; for art must allow for voluntary choice of the materials of expression by the artist. "Think the thought" is as sound as truth itself in its insistence on sincerity and honesty, but is beside the mark when it insists that all use of artifices and artful devices is wrong. The very dictionary meanings of "artful" illustrate the point; it means skilful, ingenious, in its primary sense; trickery, in a secondary sense. The artful man can be a cheat, but he does not have to be. It is entirely possible for an artist to choose artfully the media of his art and still not lay himself open to the charge of being artificial.

Just one other criticism of the most rigid application of the "thought" school: in its insistence that character makes expression it overlooks the fact that expression also makes character. It is psychologically sound that a sure way of making yourself believe a notion is to act as if you considered it true; you will in time come to accept it. So with expression; it can be so taught that the use of given devices of speech will throw the speaker into a given mood or attitude of thought. Kneel and you feel humble, throw out your chest and you become aggressive. Talk in a weak, piping voice and you lose initiative; use a rolling, resonant, orotund voice and you experience the reaction of a serious, even solemn, frame of mind. Shout, and audiences seem less terrible. Use an abundant variety of inflection and your thinking machinery is lubricated. 
Speed up and get nervous; slow down and feel calm. Thought is so comprehensive a thing that it cannot be pinned down to a few processes, and it is affected by many more factors than just good intentions.

Therefore, "think the thought" is not a complete system, though a necessary foundation and a fine corrective of abuses; especially where insincerity and dishonesty are likely to turn artifices and artistic effects into artistic chicanery and artful trickery. Its keynote cannot be left out of any ultimate system that harmonizes the various factors of expression.

d) The paraphrase system.-An offshoot of the "thought system" is that based on paraphrasing the thought before trying to express it. There is much to say in its favor; yet it accounts for only a small proportion of the factors involved in speech. In reality it is a specific and sensible device - note the word-for helping the speaker to think his thought. It is especially helpful when the speaker is to express thought composed by someone else; that is, it is chiefly helpful in the interpretation of literature.

The principle is as follows: When you feel that you have not really grasped the thought of the passage, write a paraphrase of it; amplify it; state it in other images; invent new images in order to make the thought clear; make it more concrete; utter it in your own language-use any means to make yourself see the meaning clearly and grippingly.

This is excellent advice; its greatest contribution is that it supplies the mind with more stuff to work with. It enriches the store of images, which are the chief material of thought. A mind thus enriched can obviously express itself better than one which is lean and impoverished. Many a passage yields up its treasures only after being sifted with a paraphrase. Paraphrase makes the meaning clear to the speaker; and it is perfectly obvious that the speaker, without clearness of meaning in his own mind, has little chance of carrying clearness of meaning to the mind of another.

But, like the others, it is not a complete system. There are still the listener and his hearing machinery and his imperfect mind. Where the "paraphrase system" has been united with a judicious study of the "elements" it has achieved some very satisfactory 
results, ${ }^{\text {I }}$ but only by sharing jurisdiction with other " systems." In itself it is not complete.

e) The tone system.-The latest comer into the arena of expression is the "tone system," invented by Arthur Edward Phillips. ${ }^{3}$

Mr. Phillips claims for his "system" that "in this principle, rightly applied, we have the greatest of all means by which responsiveness can be attained." He calls it "the true method of instruction," and refers to it as "such a priceless standard." With great vigor and courage Mr. Phillips insists that the "elements" systemfounded on Rush methods-must always be artificial and wasteful, and that the "think-the-thought" method-the "subjective" system-must be inane, that it cannot help the average student.

The "tone system" is based upon the contention that the true "symbol" of expression is the tone of voice in which we utter our feelings; that every sentence, clause, phrase, word, has its characteristic tone; that we can discern this tone even though we do not know the words uttered; and that it is universal in its use; language and race offering no barrier to an understanding of the tone of any given utterance. To teach expression, then, according to this "system," the prime consideration is an appreciation of the tones most commonly used in daily speech and in the interpretation of literature. By means of a system of comparison between commonplace utterances and those of classic pattern, the learner is enabled to go from the known to the unknown, and thus by ${ }^{66}$ reference to experience" to master the feeling element of any selection. Emphasis-as he denominates the logical factor in speech-is provided for under the rubrics Prominence, Articulation, and Pause. Throughout there is reiteration of the stock advice to speakers common to all books ever written on the subject; so, in this phase of the system there is little that is unique or worthy of special comment. The core of the system is found in the contention that the proper elements of speech are these four qualities: Tone, Prominence, Articulation, and Pause. On this basis must criticism of the system rest. As Mr. Phillips' defense of his system is

\footnotetext{
I See Clark and Blanchard, Principles of Vocal Expression, Chicago, I904.

2 See The Tone System, I9I0, and Natural Drills in Expression, I9o9, The Newton Co., Chicago.
} 
particularly vigorous, any strictures on it may well be carefully detailed and vigorous in turn.

The first criticism is that it must fail in that kind of public address where the speaker's chief purpose is to inform. It is not enough to pass off the whole issue by saying that the student can find the tone of Explanation in the exercises on page 39 of "Natural Drills in Expression," or that "in its purest form it (the tone of Explanation) indicates simply a desire to make plain, to tell what the thing is or how it happened. It is akin to Frankness. Usually there is a tinge of Geniality." Now experience in teaching young men and women how to utter their thoughts effectively shows that they are helped not a whit more by the charge to use the tone of Frankness or Geniality or Explanation or Uproar or Moaning than by any other kind of hint the teacher can give. It is in their inability to find out what to do about it when they know they want to be frank or genial that they fail. Even when they know that it is Explanation and Uproar that they must express, still they do not know how to express it. The difficulty lies very much deeper. Yes, the retort will be, "They are taught how to get the right sentiment by the tone drills." But this brings us to a second objection.

It is this: the tone system cannot catch the inapt student. The writer has tried the system and knows that bright boys and girls will do very nicely at getting the idea of the tone drills; but then these same bright ones get on with almost any kind of a system under a teacher who knows anything about the subject and who can give competent example and criticism. They are just naturally good at expression, and under any system at all are a delight to the teacher who teaches them. They even make good under a faulty system and poor teaching. It is not the system that makes them what they are.

As a pedagogical principle, a system must be judged by its success with the boy or girl who is not apt, who is a plodder, who must be taught from the rudiments up. In expression this means the boy or girl who perchance is tone blind, who lacks responsive vocal apparatus, who has to be made over from the faulty methods of the grade schools and the entire absence of method in the high

${ }^{s}$ Natural Drills in Expression, p. I. 
school, who is bashful, who comes from a home where proper speech methods are unknown, and, worst of all, who is deaf or blind or senseless in the interpretation of thought and sentiments. Any kind of a system will get results with the bright ones under a teacher who is also bright. But can a system be a system in fact unless it can stand the test of really teaching the slow ones?

The inventor of the tone system will have to admit that many teachers have turned out good interpreters and readers under both the despised "elements" system and the "think-the-thought" system. Each of these can point to some distinguished products, and none of us can say them nay. Where these systems have failed, then, must be in dealing with mediocre or dull pupils. What is the tone system going to do for a boy or girl who cannot identify the right tone? "Make a tonal analysis." But how can a student make a "tonal analysis" that will help him if he makes a wrong guess as to the tone he ought to pick? There is no royal road to accuracy. Why will not such a one bring up just as wide of effective interpretation as the one who uses the "elements" in a wooden manner or who fails properly to "get the thought"? Again, why is the tone system after all not merely another turn on thinking the thought with a difference merely in the emphasis in the way of thinking it? To select a name for a tone is only a kind of analysis of thinking the thought. Is not tonal analysis just as capable of wild and absurd mistakes in judgment by the dull ones as any other system that is also aimed at the bright ones?

The next objection is that the tone system cannot offer a full teaching method because it is based on a false conception of speech elements. Teaching must rest on proper analysis and judicious synthesis. No one will deny this. But if the analysis into elements is based on a misconception of the identity of elements, then the system must fail as a means of sound instruction. And the tone system misconceives the true elements of speech. According to The Tone System (p. 23), the elements are "Articulation, Prominence, Pause, and Tone." The author himself grants that this classification may be unscientific, but defends his position on the ground that it is useful and that it frees the student from "mechani-

I The Tone System, pp. 86-92. 
cal, analytical exactness." Certainly vocal methods are not properly analyzed when they are reduced to a foundation of "Articulation, Prominence, Pause, and Tone." We could agree to this classification as valuable if we were not asked by it to consider tone an element. Most decidedly it is not, and cannot be treated as such. Of course, right here is the crux of Mr. Phillips' contention: tone should be treated without a resolving into other elements, he argues. If this is an untenable position, the system fails in its handling of the student who must be taught and not asked to imitate.

If we are to teach the proper use of tone, how can we escape the consideration of its elements? What are they? Nothing less than the much despised pitch, time, force, and quality. While the "tone system" acknowledges this division of tone into elements (p. 4), it objects to the use of them because the "student does not think in those terms at all in considering tone." "He [the student] takes the sound as a synthetic whole and understands it to represent certain thoughts and feelings. Never for a moment does his mind dwell upon force, quality, abruptness, as such, and if it did the probability is that the thoughts and feelings would be wholly lost to him" (pp. 22-23). But by what royal decree are we to know that this same student can think in terms of tones any more than in considerations of pitch, force, and quality? Conceded that the bright pupil can catch onto the tones, so also can he to considerations of pitch and quality. This student can be made to do effective work under any system that keeps him at work and interested in his task. But can a system be a teaching system in reality if it invents new elements and wipes out elements that cannot be denied as genuine and fundamental?

We say fundamental, because speech is nothing other than the use of vocal sounds - tones - that carry meaning, and the elements of these are pitch, time, force, and quality. There is no known way of resolving the tones of the voice to elements other than these. True, we can describe the meanings of sounds as expressing admiration, affection, indignation, and the rest of the fifty-seven. ${ }^{2}$ But we add nothing that looks like an element. Tone is most emphatically a compound. As Phillips insists, it is tone that carries

\footnotetext{
I The Tone System, p. 26. $\quad$ ' See Table of Contents, Natural Drills.
} 
meaning. Yet descriptions of meanings are not elements. They are not what the speaker uses or what the hearer receives. And no system of teaching can be complete that uses for elements something other than the unresolvable. Every tone made by the human voice is a compound of pitch, force, time, and quality; there is no escape from this.

Yet the "tone system" contains a core of truth. Where, then, does it fit into expression? The answer is far from difficult. "Tone" simply represents the element of purpose that must be behind the presentation of every idea offered for the consideration of hearers. Always behind what is uttered lies an intention, a personal attitude, a desire, which is best expressed by the idea of purpose. It is what is sometimes thought of as the inner meaning. This element of purpose it is that produces all speech-malking and marks the difference between one speech and another and one tone and another. A man expresses admiration because it is his intention to make another see that he feels like that and presumably wants the other man to feel it too. In the interpretation of literature the speaker merely talkes other men's purposes-inner meanings-as a loan; and it is because so many boys and girls cannot see what they are borrowing that the tone system can be helpful. By its scheme of comparison it very often helps the uninitiated to understand what he is borrowing and to suggest to what use it can be put. But it is very far indeed from the whole of the process of expressing thought. There is more to speech than purposemuch more.

There is thought content. The Tone System treats this in one page, merely a new turn on thinking the thought, "group words wisely and give prominence where prominence belongs" -in other words, think it out before you speak. Any advocate of thinking the thought could approve of this heartily. But it is open still to the objection that it ignores the listener and his needs.

Unless a system provides for ultimate analysis it cannot be properly taught. Therefore a complete system cannot be buillt up without consideration of the "elements." Now this does not necessarily advocate such an "elements system" as The Tone

$\therefore$ Pp. 96-97; see also Nabural Drills, P. 84. 
System pictures. Mr. Phillips has set up a horrible straw man with only a vocal machine and no brain or "innards" of any kind; a specimen that in real life is lost and gone forever, we hope; an extinct species, except possibly in a few rare instances. In order to make use of the elements it surely is not necessary to misuse them. The Tone System seems to think it is; but there is something more to painting than paint and to architecture than bricks and beams. The elements can be used as a means of telling why and of explaining how. In this capacity they are indispensable to a teaching system. Beyond this they lead to woodenness, absurdity, juicelessness-or excess of juice.

We have said that all these so-called systems have a part in a proper educational science of elocution. It is not difficult of demonstration. Let us try it:

Speaking - and its foster-sister, interpretation-is always an attempt to carry thought from one mind to another. Thought is always and unfailingly the foundation of speech. So "think the thought" is the soundest advice in the world-as far as it goes. The trouble is that the term "thought" is exceedingly vague to most minds. There are at least two aspects to thought as applied in expression: first, thought content, or the objective logical meaning of the word symbols. This is what comes to the mind when the words are written on paper or uttered merely so as to be audible and intelligible; that part of thought on which we could pass an examination after we have read it or heard it spoken. Thought content has to do with logical relations. To say that it is necessary to think out the force of this logical content is simply to state the obvious. The thought must be previously mastered.

The other aspect of thought is its subjective meaning, the personal attitude of the man who utters it; its feeling content; what a sheet of paper often cannot show and what the voice always can; in fact, that inner meaning without which vocal utterance is colorless and dead. It is what we rather vaguely call a show of personality; or, again, it is thought expressed artistically as against commonplace. Fundamentally it can be brought down to purpose, what the speaizer intends by his words. It is the basis of "tone." So "thinking the thought" must be more than passing a quiz 
on thought content. The contribution of Mr. Phillips to the task of thinking out the thought is in devising a very helpful scheme for locating this evasive and subtle feeling attitude, this purpose. The tone drills, with most students, are a help in identifying and expressing purpose.

But there are degrees of difficulty in getting the thought thought out. When it is stubborn and refuses to come from its hidingplace there is a device that helps very materially. Enter paraphrasing. This is only a more intensive method of thinking out the thought. When your voice does not seem to get the results you want, go over the ground more minutely and see what it is you are trying to express. Say the thing in different words, and very likely you will get a better grip on its possibilities. This is excellent advice and very helpful, and sound pedagogy withal.

What follows? Sometimes the thought is clear enough in the student's mind. He can pass a written test on its logical content and label it with the right "tone" and make an excellent paraphrase of it. All of this he can accomplish by "scowl of brow"; but, alas, very often the best paraphrasers and tone analyzers give forth the most excruciating sounds when they turn their findings into speech. They are monotonous or commonplace or merely fantastic. Their matter simply does not get.across. What is the answer?

Behold, the "elements." The only way to get at a pupil whose thinking does not guide him aright is to take the thing apart and show him how it works. Better yet, as a matter of teaching it is the one best way - after the thinking of the thought has been doneof developing the student's powers of self-criticism and of cultivating good speech habits. No system is complete that does not make its products into keen and accurate analyzers; not only of their own work, but even of the work of others. A taught student ought to be a good diagnostician and ought accordingly to be in the way of improving himself and of teaching others.

The ultimate way of doing this is to analyze tone. This means a considering of the effects of changes in pitch, time, force, and quality. Speech is a matter of sounds the voice makes. These sounds carry meanings. Meaning is carried by changes in the 
elements; to get the right meaning, choose and use the right changes in elements. When it is necessary to analyze to the bottom, then the study of these elements becomes a study of the changes that produce right meanings. A few simple rules go a long way toward showing pupils what changes in the use of the elements accomplish corresponding changes in the thought.

Then, finally, with any "system" it is well for the teacher to give occasional examples of good expression. It helps the student to accumulate a proper supply of auditory images of good kinds of expression. It is even more profitable to the student to hear great actors, great readers, and effective orators. There is always something for the artist to learn from every work of art that he witnesses. So imitation plays its part and is a factor in expression.

Thus we have provision for all the "schools"-think the thought, the tone system, paraphrasing, the elements, and imitation. All are needed; all are useful. But no one by itself is a system complete. Think out the thought, paraphrase ideas, label tones, follow good models; but when you are trying to tell what expression really is to a college class of intelligent boys and girls, who are also studying rhetoric and psychology and chemistry, you have no possible way of getting at the final teaching basis of your subject unless you talk pitch, time, force, and quality, just exactly as the teacher of rhetoric talks unity, emphasis, syntax, and clearness, or the teacher of psychology talks sensation, idea, affection, and will, or the teacher of chemistry talks of metals, salts, gases, and alkalis. On no other grounds can we stand before the educational world and pretend that we are resting our art upon a foundation of science. And can there be any other basis for teaching than the use of rules as a means of perfecting practice? 